\title{
EM BUSCA DA MELHORIA CONTÍNUA: ALTO DESEMPENHO ORGANIZACIONAL ATRAVÉS DE GESTÃO DE PROCESSOS
}

\author{
SEEKING OF CONTINUOUS IMPROVEMENT: HIGH ORGANIZATIONAL \\ PERFORMANCE THROUGH PROCESS MANAGEMENT
}

Cesar Moser Ramos Centro Universitário Ritter dos Reis (UniRitter), Pontifícia Universidade Católica do Rio Grande do Sul (PUCRS).

Betina Magalhães Bitencourt Mestre em Administração pela Universidade Federal do Rio Grande do Sul (UFRGS). Doutoranda em administração (UFRGS) e professora colaboradora do Centro Universitário Ritter dos Reis (UniRitter).

\section{RESUMO}

Em um cenário de oscilações econômicas e sociais, competição entre organizações e constantes avanços tecnológicos, o gerenciamento focado em melhorar continuamente se mostra um requisito necessário para alcançar uma gestão que obtenha resultados de alto desempenho em nível organizacional e mercadológico. $\mathrm{O}$ objetivo deste trabalho é compreender quais são os principais resultados que a gestão de processos, através de indicadores de desempenho, proporciona para um negócio e buscar identificar os principais motivos que levam um gestor a adotar ou não essas ferramentas.

Palavras-chave: Gestão de Processos; Melhoria Contínua; Indicadores de Desempenho; Gestão da Qualidade.

\section{ABSTRACT}

In a scenario of economic and social fluctuations, competition with organizations and constant advances in technology, the management focused on continuously improve shows itself a necessary requisite to achieve management to obtain high performance results at the organizational level and market. The objective of this study is understand what are the key results the process management through performance indicators provide to business and seek to identify the key points that lead a manager to adopt these tools.

Keywords: Process Management, Continuous Improvement, Performance Indicators, Quality Management. 
Introdução

Com a internacionalização da economia, as mudanças de mercado, os constantes avanços tecnológicos e dos sistemas de produção, as organizações se veem em um novo ambiente competitivo. Isso faz com que procurem um maior alinhamento com as exigências mercadológicas, econômicas, ambientais e sociais (OLIVEIRA, 2006).

Partindo deste pressuposto, a presença de indicadores que estejam alinhados com a realidade organizacional do negócio e ao fácil entendimento dos gestores torna-se indispensável para alcançar resultados satisfatórios de gestão nesta realidade. Segundo a conhecida ideia de Deming (1990), não se consegue gerenciar o que não se mensura, não se mensura o que não está previamente definido, não se define o que não está de claro entendimento, sendo assim, não existe sucesso no que não se gerencia. Porém, para que isso aconteça, é indispensável uma comunicação eficiente entre todos os níveis gerenciais na implementação dos indicadores e na definição das metas, evitando que sejam desenvolvidas análises e metas que não estejam alinhadas com os objetivos da empresa.

Mapear e definir os processos a serem medidos são fatores fundamentais e que norteiam o responsável pelo desenvolvimento dos indicadores de desempenho. A ausência de um mapeamento bem executado pode culminar em um conjunto de indicadores imprecisos, ou que pouco serão úteis à tomada de decisões na organização.

O adequado mapeamento de um processo, aliado a indicadores de desempenho precisos e que estejam alinhados com a estratégia do negócio proporcionam um ambiente propício à implementação de uma gestão focada na melhoria contínua. Esta, por sua vez, tem um destaque especial neste artigo, pois a gestão através da melhoria contínua proporciona um processo constante de aprendizagem organizacional, que é de grande valia para o crescimento de uma empresa.

Ainda que os benefícios de uma gestão com base em processos e indicadores de desempenho sejam conhecidos, observa-se que há um grande número de empresários que não adotam tais conceitos na gestão de seus empreendimentos. Portanto, buscou-se na realização deste estudo de caráter qualitativo descrever e compreender as principais mudanças que os gestores esperam ao gerenciar processos com o uso de indicadores e identificar os principais 
motivos que induzem os gestores a utilizar ou não tais ferramentas.

Dessa forma, este estudo justifica-se como uma contribuição para entender quais são as principais vantagens de adotar a gestão de processos, em utilizar indicadores de desempenho e a aplicar conceitos de melhoria contínua em setores específicos e também em âmbito organizacional. Além disso, traz a discussão a respeito da não utilização destas ferramentas por parte dos gestores.

Para tanto, este estudo tem como base os principais conceitos acerca das ferramentas de uma gestão de processos, partindo do mapeamento destes, do uso de indicadores de desempenho, da busca pela melhoria contínua e dos resultados esperados na gestão. Após a fundamentação teórica, discorre-se a respeito do método que norteou a pesquisa, seguido da apresentação e análise dos resultados, e das considerações finais.

\section{Mapeamento dos Processos}

Conhecer os processos do negócio nos permite identificar as falhas e corrigilas, almejando alcançar a excelência, reduzindo as perdas em produção e buscando a satisfação do cliente com o produto final. De acordo com Goldratt (2001), para ampliar os resultados de um negócio é necessário identificar as falhas do sistema, eliminá-las, identificar outras falhas e seguir melhorando.

Sendo assim, o processo bem gerenciado e sistematicamente definido permite obter uma otimização de recursos disponíveis, tais como: tempo, matériaprima, mão de obra e espaço físico. Todavia, para gerenciar bem um processo é necessário primeiramente entender

o que ele significa. Segundo Scartezini (2009), processo é uma ordenação de atividades de trabalho no tempo e no espaço, com um começo e um fim claramente identificados. Para conseguir aperfeiçoar um processo em busca dos melhores resultados é vital saber onde estão os inputs (entradas) e outputs (saídas), definindo quem será responsável e quais as premissas para cada uma.

Planejamento em muitos casos pode ser considerado vital para o sucesso, pois permite que, através de análises das alternativas potenciais de ação, se obtenha os resultados almejados ou se identifique um ponto de inconformidade. Assim, é possível agir previamente, evitando ocorrências que se oponham ao objetivo esperado. De acordo com Ghinato (1996), o planejamento identifica as 
alternativas potenciais para a ação, de maneira que possa satisfazer o objetivo. Conhecer os fatores e questões envolvidos no negócio auxilia a escolha da melhor alternativa a ser seguida durante o planejamento de determinada atividade.

Após conhecer o processo, busca-se a transposição do mesmo em forma gráfica, para que mais pessoas tomem conhecimento das atividades e restrições contidas neste, também possibilitando a correção de eventuais inconformidades. Conforme Scartezini (2009), mapear é transpor de uma maneira gráfica a sequência de atividades dentro de um processo, utilizando-se da ferramenta fluxograma para representá-lo. Portanto, mapear é fundamental para identificar as falhas e, se não for transposto para uma análise gráfica, muitos processos ficarão somente sob o conhecimento de quem trabalha diretamente com ele.

\section{Indicadores de Desempenho}

O uso de indicadores mostra-se necessário para poder controlar os principais pontos de desperdício, as falhas nos processos e poder direcionar os esforços para repará-los, pois, sem o uso deles, alguns erros podem passar despercebidos no dia a dia pelo gestor e dessa forma não serem corrigidos. Scartezini (2009) enfatiza a importância da utilização dos indicadores de desempenho na gestão, uma vez que eles são formas de representações quantificáveis das características de um processo, além de seus produtos ou serviços. Os indicadores são utilizados para controlar e melhorar a qualidade e desempenho destes em longo prazo.

Deve-se, ainda, utilizar os indicadores de desempenho para monitorar a proximidade que determinada atividade/processo está de sua meta. Hronec (2001) afirma que os indicadores de desempenho ou de performance organizacional podem ser considerados sinais vitais do negócio, pois eles conseguem quantificar e qualificar a maneira como as atividades ou outputs (saídas) de um determinado processo atingem suas metas pré-estabelecidas.

Alerta-se, ainda, que indicadores imprecisos podem "incriminar" atividades, processos, pessoas e até mesmo condenar setores, pois existem várias formas de analisar um problema ou um sucesso. Se um indicador for estabelecido por uma única pessoa sem o consentimento e aprovação de mais pessoas envolvidas, esse indicador pode privilegiar determinado ponto de vista.

Neely e Austin (2000) classificam esse fato como "miopia da medição". A 
miopia na medição nada mais é do que quando a empresa/setor está medindo coisas erradas e tomando decisões a partir dessas medições. Eles também destacam outro fator que deve ser ponderado, a "loucura da medição", que é quando gestores são obcecados por medição e desejam medir tudo, criando indicadores onde não existe a necessidade de medição. Para que isso não aconteça, é fundamental conhecer todos os processos do negócio, junto a isso é recomendado dispor do fluxograma do mesmo, pois sem o claro entendimento dos inputs e outputs do processo, os envolvidos no estabelecimento dos indicadores de desempenho podem criar indicadores "míopes" ou "loucos".

Levando em consideração que toda a medição exerce um efeito sobre quem ou o que está sendo medido (MARTINS, 1998), a utilização de indicadores de desempenho pode ser utilizada como uma fração da linguagem da melhoria contínua. Proporcionando a indução dos colaboradores da organização em prol do atingimento dos objetivos de melhoria em nível individual e organizacional.

\section{Melhoria Contínua}

Busca-se através do estabelecimento dos processos e monitoramento por meio de indicadores capacitar a empresa em busca da melhoria contínua. Esta pode ser considerada um diferencial competitivo, pois tem por objetivo garantir credibilidade e eficiência para as empresas perante o mercado, uma vez que as direciona para a otimização dos processos e eliminação de falhas, proporcionando padronização e qualidade para os produtos.

A melhoria contínua é um elemento fundamental às práticas da qualidade, podendo ser desenvolvida como uma ferramenta a parte, tendo seus fins próprios ou servindo de base para programas de qualidade mais complexos, tais como a família ISO e o Seis Sigmas. A implementação da ideia de melhoria contínua busca evoluir sistematicamente os processos, produtos e serviços, superando dificuldades, solucionando problemas, aprendendo com erros e acertos, ensinando, conhecendo, compartilhando e contribuindo tanto para o crescimento do indivíduo como da organização (BESSANT; CAFFYN; GALLAGHER, 2001).

Sendo assim, após transformar o processo em uma análise gráfica, que possa ser analisado e visualizado por todos os envolvidos no seu gerenciamento, e também medindo os seus resultados através de indicadores de desempenho, 
começam a aparecer pontos de melhoria e correção, que devem ser organizados para identificar quais serão priorizados. Com isso, tem como foco uma gestão que busca melhorar continuamente, criando um diferencial competitivo através da qualidade.

A melhoria contínua tem como suporte o controle e a otimização dos processos e foi a base para a Metodologia da Gestão da Qualidade Total. Através do ciclo PDCA busca-se monitorar os processos produtivos para a melhoria contínua gradual (Kaizen), através da identificação e análise de resultados indesejáveis e da consequente busca de novos conhecimentos para auxiliar nas soluções (RODRIGUES, 2006, p.18).

Para auxiliar a implementação da melhoria contínua organizacional utilizam-se algumas ferramentas de suporte, Gerolamo (2003) transpõe o ciclo PDCA (planejar, fazer, verificar, agir) para ser utilizado no gerenciamento da melhoria e mudança de desempenho organizacional, conforme se segue:

1. $\quad \mathbf{P}$ (plan): identificar e analisar as estratégias dos processos e planejar as estratégias futuras. Orienta-se que o processo de formulação da estratégia deve ser revisto continuamente;

2. D (do): com o direcionamento estratégico, pode-se partir para a identificação e implementação das ações de melhoria e mudança dentro dos processos;

3. C (check): avaliar, verificar os resultados obtidos e dar o feedback necessário, comparando os resultados com as estratégias atuais e futuras;

4. $\quad$ A (act): documentar as lições aprendidas pelas ações implementadas e consolidar a melhoria e mudança adquirida.

A utilização de ferramentas de qualidade e métodos interativos de gestão serve para organizar, estipular prazos, definir responsáveis e elencar em ordem de prioridade as ações de mudança dentro dos processos e na formulação dos indicadores. Também é útil para padronizar a comunicação das mudanças e transpor de maneira clara o que está sendo feito ou planejado.

É recomendado que as empresas que buscam a melhoria contínua estejam focadas no monitoramento de indicadores de processos e na correção das falhas identificadas, para que dessa forma consigam obter sucesso e aprendizado. Cabe ressaltar que esse processo muitas vezes é desgastante e exige um 
comprometimento geral dos colaboradores que estiverem envolvidos com esses controles. Robbins (2002) diz que a melhoria contínua mostra-se contrária às tradicionais abordagens norte-americanas da administração, que é ver a realização do trabalho como algo linear, com um começo e um fim, pois a busca pela melhoria contínua resulta em uma corrida sem linha de chegada, uma vez que a filosofia kaizen acredita que seja sempre possível fazer melhor.

\section{Resultados esperados na Gestão}

Com todas as ações previamente estabelecidas na etapa de construção, mapeamento, planejamento e controle dos processos busca-se maior qualidade, tentando minimizar, assim, a entrega de um produto ou serviço que gere risco para o negócio. Para Chowdhury (2005) ter uma baixa qualidade traz uma série de prejuízos para a empresa em termos financeiros e da sua imagem, podendo colocar em risco o sucesso do negócio.

Ao adotar uma ferramenta de gestão orientada para a qualidade, o gestor deve ter como principal objetivo ampliar a eficiência do seu negócio e também conquistar a fidelidade do seu cliente, por meio da percepção de qualidade no produto ou serviço entregue. Dessa forma, o negócio poderá tornar-se sustentável em longo prazo e, ainda, contará com a fidelização e divulgação da marca pelos clientes. Para Thompson e Stricland (2000), empresas onde os gestores estão orientados a estabelecerem objetivos para cada área chave de resultado e buscam ações calculadas para atingir suas metas de desempenho naturalmente superam as concorrentes cujos gestores apenas se apoiam em intenções boas e aguardam o sucesso.

\section{Método de Pesquisa}

Este estudo caracteriza-se de natureza qualitativa, pois busca explorar dados e características dos indivíduos, além dos cenários que não podem ser facilmente descritos numericamente. Assim, buscou-se na coleta de dados verbais, por meio da observação, descrição e gravação a construção dos resultados deste estudo (MOREIRA; CALEFFE, 2008). E de caráter descritivo, pois tem por objetivo a descrição de fatos e acontecimentos, ou seja, como se dispõe determinado 
fenômeno (SAMPIERI; COLLADO; LUCIO, 2013). Quanto à estratégia de pesquisa, foi utilizada o estudo de caso múltiplo, que é considerado uma investigação empírica que busca compreender um fenômeno recente dentro do seu contexto real, justamente quando as barreiras entre o fenômeno e o contexto não estão claramente descritos (YIN, 2005). O estudo de caso é adequado neste caso, uma vez que pode ser considerado um estudo que atinge o fenômeno, mas não amplamente, e proporciona conhecer profundamente alguns poucos elementos da população sobre um grande número de aspectos e suas inter-relações (MATTAR, 1994).

Para tanto, optou-se por elencar alguns participantes que atuam em empresas do Rio Grande do Sul, sendo dos ramos da educação e prestação de serviços para empresas, como serviços automotivos, construção civil e consultoria. Além disso, buscamos a participação de um consultor atuante na área da qualidade, com o objetivo de levantar os dados propostos pelo estudo e compará-los com os demais participantes que atuam em empresas de diferentes ramos de atuação.

Optamos pela participação de profissionais de empresas de setores distintos, com o intuito de coletar opiniões com diferentes perfis de atuação e identificar pontos convergentes ou divergentes nas respostas. Para isso, foi elaborado um roteiro de perguntas estruturado, disponibilizado e respondido pela Internet. Através de e-mail e contato telefônico os participantes foram informados que o questionário já estava disponível para preenchimento e após isso começaram a respondê-lo prontamente. A escolha dos participantes se deu por contatos pré-estabelecidos de um dos pesquisadores e todos os contatados aceitaram o convite para participar da pesquisa desde que esta fosse realizada por um meio facilitado de acesso, por isso, a utilização do meio eletrônico de acesso aos dados.

A Web proporciona um método de coleta e de disseminação das informações nunca antes possível de ser consolidado. Através dela, o pesquisador não possui limites às restrições do tempo, distância e custo, já que o acesso é livre, com despesas baixas e praticamente instantâneo. Ainda assim, o tipo de questionário a ser gerenciado pode desviar as tradicionais impressões, permitindo que o pesquisador utilize uma interface muito mais amigável e completa, seja no momento em que coleta os dados ou apresenta-os (FREITAS; JANISSEK- MUNIZ; BAULAC; MOSCAROLA, 2006). Por isso, foi escolhido este meio para contato com os participantes, pois todos tinham acesso facilitado a internet e a utilizam largamente também no meio de trabalho, sendo, portanto, mais adequada para coleta de dados 
segundo o propósito do estudo.

Para analisar os dados foi escolhida a análise de conteúdo, que surgiu no início do século XX nos Estados Unidos para analisar o material jornalístico, podendo ser quantitativa ou qualitativa. $\mathrm{Na}$ abordagem quantitativa traça-se uma frequência das características que se repetem na entrevista (CAREGNATO; MUTTI, 2005), já na abordagem qualitativa se "considera a presença ou a ausência de uma dada característica de conteúdo ou conjunto de características num determinado fragmento da mensagem" (MADS, 1993, p. 53).

A partir da análise dos dados qualitativos obtidos nos questionários aplicados, foi possível identificar as principais opiniões e, em alguns casos, os entraves para implementar sistemas voltados para a melhoria contínua. Os dados obtidos buscaram atender aos objetivos da pesquisa e serem passíveis de comparação com a literatura mencionada.

\section{Apresentação e Análise dos Resultados}

Através dos questionários aplicados foi possível compreender as principais opiniões dos entrevistados acerca da gestão de processos e o uso de indicadores de desempenho para mensurar os resultados. Todos os participantes responderam os questionários de forma completa, não desconsiderando nenhuma pergunta e de maneira clara, sem desviar do tema proposto.

Para simplificar a compreensão das principais características dos entrevistados, o perfil de cada um foi disposto no Quadro 1. Dessa forma, é possível visualizar o perfil dos participantes da pesquisa e também consultar, assim que necessário, as informações contidas no quadro.

\begin{tabular}{|c|c|c|c|c|c|c|}
\hline Participante & Idade & $\begin{array}{l}\text { Formação } \\
\text { acadêmica }\end{array}$ & $\begin{array}{l}\text { Atividade na } \\
\text { empresa }\end{array}$ & $\begin{array}{l}\text { Segmento } \\
\text { em que } \\
\text { atua }\end{array}$ & $\begin{array}{l}\text { Tempo de } \\
\text { atuação } \\
\text { na } \\
\text { empresa }\end{array}$ & $\begin{array}{l}\text { Porte da } \\
\text { Empresa }\end{array}$ \\
\hline Participante 1 & $\begin{array}{c}26 \\
\text { anos }\end{array}$ & Administração & $\begin{array}{l}\text { Gerente de } \\
\text { Produção }\end{array}$ & Automotivo & 3 anos & Pequena \\
\hline Participante2 & $\begin{array}{c}29 \\
\text { anos }\end{array}$ & $\begin{array}{l}\text { Gestão da } \\
\text { Qualidade }\end{array}$ & $\begin{array}{l}\text { Coordenador de } \\
\text { Planejamento }\end{array}$ & Educação & 4 anos & Grande \\
\hline Participante3 & $\begin{array}{c}35 \\
\text { anos }\end{array}$ & $\begin{array}{l}\text { Relações } \\
\text { Públicas }\end{array}$ & $\begin{array}{l}\text { Coordenador de } \\
\text { Relacionamento } \\
\text { com Empresas }\end{array}$ & Educação & 1 ano & Grande \\
\hline
\end{tabular}




\begin{tabular}{|c|c|l|l|c|l|c|}
\hline Participante4 & $\begin{array}{c}34 \\
\text { anos }\end{array}$ & Administração & $\begin{array}{c}\text { Diretor de } \\
\text { Relacionamento } \\
\text { com o Cliente }\end{array}$ & $\begin{array}{c}\text { Serviços de } \\
\text { Construção } \\
\text { Civil }\end{array}$ & 5 anos & Pequena \\
\hline Participante5 & $\begin{array}{c}59 \\
\text { anos }\end{array}$ & $\begin{array}{l}\text { Economia e } \\
\text { Técnico em } \\
\text { Mecânica }\end{array}$ & $\begin{array}{l}\text { Consultor de } \\
\text { Empresas }\end{array}$ & $\begin{array}{c}\text { Setor } \\
\text { Industrial }\end{array}$ & 20 anos & Micro \\
\hline
\end{tabular}

Quadro 1 - Perfil dos participantes

Fonte: elaborado pelo autor

Foi possível identificar uma convergência de opiniões sobre a adoção de uma gestão focada em processos definidos e organizados e a adoção de indicadores de desempenho. Ficou claro que a expectativa de cada participante sobre as ferramentas é que elas sirvam de apoio à gestão e à tomada de decisões, como podemos notar no relato de um dos participantes, quando questionado se mapear e documentar os processos facilita o trabalho: "sim facilita, pois uma vez que eles estão documentados é possível fazer avaliações constantes e visualizar com mais clareza os pontos que devem ser melhorados" (Participante 1).

Todos os participantes afirmaram ter conhecimento sobre os processos que gerenciam, conforme relata o Participante 1, "os processos que são mais utilizados no dia a dia estão documentados e de fácil acesso para todos os envolvidos na realização do mesmo". Considera-se que esta organização é muito importante, pois facilita a solução de falhas pontuais nas atividades, estimulando o gerenciamento das mesmas. Além disso, por meio dessa organização ficam visíveis os inputs e outputs, proporcionando a melhoria contínua, conforme enfatiza Goldratt (2001).

Identificou-se ainda a importância da participação de todos os responsáveis pela gestão do setor/empresa na hora da definição e mapeamento dos processos, como relata o Participante 2: "há pontos negativos quando o material não contempla o público alvo a quem foi desenvolvido. Ora pela complexidade dos termos utilizados, ora pela falta de objetividade e clareza com que foi concebido". Com a ausência de uma ou mais pessoas envolvidas nos processos que estão sendo mapeados, existe a possibilidade de alguma etapa ser esquecida ou transcrita de uma maneira inadequada ao entendimento de quem está diretamente relacionado com a gestão da atividade.

A pesquisa possibilitou-nos constatar, também, que todos os entrevistados que utilizavam indicadores de desempenho o faziam com o auxílio de dados estatísticos. Estes tinham por finalidade mensurar e quantificar cada etapa dos 
processos. O Participante 1 detalha com clareza os indicadores que utiliza na sua empresa: "utilizamos indicadores estatísticos de processos, de performance individual, de capacidade de produção, de retorno financeiro e de satisfação dos clientes e funcionários".

É de suma importância os indicadores estarem alinhados com a realidade da empresa, eliminando indicadores excessivos e que pouco agregam ao seu contexto, evitando assim que haja a "loucura da medição" (NEELY; AUSTIN, 2000). Através dos questionários foi possível identificar que os participantes concordam que toda a medição deve ser clara para todos os envolvidos e ter um propósito bem definido, pois o processo de análise dos resultados requer responsabilidade e minuciosidade por parte de quem está à frente dele, e criar indicadores sem propósito é desperdiçar tempo de funcionários capacitados.

Quando questionados sobre quem desenvolvia os indicadores, as respostas ficaram divididas, mas foi possível identificar que sempre há a participação de mais de um colaborador no desenvolvimento destes, evitando assim uma "miopia da medição" no desenvolvimento dos indicadores, conforme alerta Neely e Austin (2000). Na empresa do Participante 4, existe um setor específico para a criação e atualização dos indicadores de desempenho.

Existe a necessidade de termos um setor a parte para o desenvolvimento dos indicadores, pois como trabalhamos com mais de um gestor definindo o que deve ser medido e avaliado, a presença de um setor específico torna o controle mais confiável, sem a disputa de interesses (Participante 4).

Foi possível identificar que, mesmo que os participantes atuem em segmentos diferentes e em empresas de porte variado, suas respostas mantém um nível gerencial semelhante. Conclui-se, de maneira geral, que onde existe a preocupação em conhecer os processos e, de alguma forma, mensurar os seus resultados, há maior possibilidade de ganhos nas organizações, indo ao encontro também da literatura consultada.

Ainda que sejam verificados pontos positivos em adotar uma gestão com base em processos e melhoria contínua, verifica-se que algumas empresas ainda não o fazem. Por isso, o Participante 5, que é consultor de empresas de micro, pequeno e médio porte, foi questionado sobre quais eram os principais motivos que um empresário/gestor se deparava ao não utilizar as ferramentas propostas neste 
estudo.

O acúmulo de atividades que acarretam as empresas, principalmente no que abrangem as áreas financeiras, administrativas, processos produtivos, fornecedores de matéria prima e clientes, exigindo um sincronismo que nem sempre é alcançado internamente (Participante 5).

Dessa forma, consegue-se entender a importância de destinar um setor ou colaborador específico para ser responsável pela gestão dos processos, contando com a participação dos demais gestores somente em momentos definidos previamente (reuniões), com o intuito de buscar a aprovação do que foi definido. Busca-se, com essa organização, evitar negligência ou esquecimento durante o acompanhamento e definição dos processos.

Quando questionado sobre as principais consequências da ausência da definição de processos em um negócio/setor o Participante 5 foi muito enfático e citou a seguinte frase: "A falência, mais cedo ou mais tarde. É só questão de tempo, se o gestor ou empresário não se organizar ou procurar obter conhecimento dos processos que gerencia no seu dia a dia."

Com isso, é possível refletir e amenizar a resposta, concluindo que talvez a falência aconteça em casos isolados ou em determinado segmento, como o industrial, que exige muita organização, pois possui cadeia produtiva. Existem alguns tipos de negócios que ainda sobrevivem com uma gestão desorganizada e falha. Algumas empresas têm potencial, crescem imaturamente e se deparam com problemas sérios de gestão por falta de organização, podendo ser revertidos quando adaptados a uma realidade organizada e que possibilite e mensuração dos processos.

Identificou-se que nem todas as empresas consideram como oportuno o gerenciamento focado na melhoria em todas as áreas, conforme descreve o Participante 5, a seguir: "nas empresas que eu atuo, algumas só pensam em melhorar a qualidade na área de fabricação e esquecem que a empresa é um todo". Por isso, considera-se importante que haja uma equalização entre todos os setores no que tange o gerenciamento, pois existindo disparidade na qualidade das técnicas de gestão, consequentemente, haverá gargalos e dificuldades na gestão da empresa.

Ainda, para o consultor (Participante 5), a adoção dos métodos propostos 
neste trabalho pode induzir a obtenção de qualidade total em todas as operações de um negócio, minimizando perdas e reduzindo inconformidades. Ele relatou que muitos pequenos e microempresários procuram essas ferramentas quando elas são a última opção para dar continuidade nos negócios e, após a adoção delas, ficam surpresos como métodos simples trazem resultados e organização. O consultor também ressalta que a adoção da gestão de processos através de indicadores de desempenho é imprescindível para qualquer empresa que queira ser eficiente e competitiva no mercado globalizado.

Foi possível constatar, portanto, que atualmente, as empresas que querem crescer e sustentar-se ao longo do tempo necessitam de organização e ter respostas para os seus problemas, que através da gestão dos processos pode ser alcançada. Além disso, não utilizar algum tipo de ferramenta que proporcione uma gestão eficiente dos processos, pode induzir a empresa ao fracasso ao longo do tempo.

\section{Considerações Finais}

Este estudo buscou compreender quais são os principais resultados que uma gestão de processos orientada por indicadores de desempenho pode proporcionar para um negócio. Além disso, objetivou demonstrar os principais ganhos que a adoção desses métodos proporciona e também entender os principais pontos fazem os gestores adotar ou não os métodos propostos para a busca da melhoria contínua.

Ao concluir a análise das entrevistas foi possível identificar que os gestores tem conhecimento das ferramentas trazidas neste estudo e as classificam como importantes para o alcance da qualidade no serviço prestado ou na confecção de produtos. Identificou-se, também, que existe a preocupação por parte das empresas em adotar uma gestão focada em gerenciamento dos processos das atividades por meio de mecanismos que mostrem a situação real de cada processo, embasada em forma de análise (indicadores de desempenho). A partir destes dados, observa-se que ainda alguns empresários, sobretudo os atuantes nas organizações micro e pequenas, ainda possuem certa resistência ou falta de conhecimento destas ferramentas, mas se mostram adeptos a elas quando se deparam com situações preocupantes ou desorganizadas.

A necessidade de obter ganhos em produtividade, redução de custos e qualidade faz com que os gestores procurem alternativas para alcançar seus 
objetivos. Conhecer os processos é a base para poder adotar ferramentas que permitam a busca dessas alternativas; e a ausência de uma documentação que os formalize pode comprometer os resultados da gestão. Isso porque uma empresa que se preocupa em seguir uma estratégia, seja ela por redução de custos, qualidade e etc., não pode correr o risco de que um processo esteja legível apenas para uma pessoa, impossibilitando o debate, a mensuração e a exploração do mesmo. Essas afirmações vão ao encontro a conceitos apresentados (GOLDRATT, 2001; SCARTEZINI, 2009; GHINATO, 1996).

A melhoria contínua se prova eficiente, pois em suas premissas ela incentiva um movimento contrário a algumas ações que devem ser banidas do cotidiano dos gestores, que são: conformismo, comodismo, negligência. Essa filosofia exige que haja troca de boas práticas no ambiente de trabalho. Ela incentiva ainda a mudança de alguns métodos que podem estar comprometendo resultados $e$, consequentemente, orienta a empresa para a busca de serviços e produtos com maior qualidade (BESSANT; CAFFYN; GALLAGHER, 2001).

Este estudo propõe que, para obter sucesso ao gerenciar processos através de indicadores de desempenho, o gestor conheça bem os seus processos e transponha-os de maneira que mais pessoas entendam e debatam melhorias. É necessário controlar esses processos através de indicadores previamente estabelecidos e debatidos, pois eles garantem a confiabilidade às análises. Além disso, é imprescindível ter disciplina para seguir o que foi definido e o que foi corrigido. Dessa forma, a gestão torna-se exitosa e proporciona o crescimento coletivo.

Conclui-se, por fim, que gerenciar processos é fundamental para garantir a sustentabilidade e crescimento de um negócio. Gestores precisam ter respostas claras aos possiveis problemas do cotidiano, para agir corretivamente quando necessário. Sem a clareza e conhecimento das atividades que a empresa realiza ou realizará no seu âmbito organizacional, é pouco provável que se alcance a melhoria contínua. Melhorar continuamente exige participação coletiva e aprendizados constantes, mas, para que isso aconteça, é preciso que os gestores entendam e controlem suas atividades diárias.

Ainda que durante $\mathrm{o}$ processo de pesquisa bibliográfica tenham sido identificadas contribuições teóricas bem estruturadas e fundamentadas, adequadas com a realidade organizacional que algumas empresas se deparam, não foram 
realizados testes práticos utilizando os conceitos sugeridos neste estudo, dessa forma, existe uma limitação prática neste estudo no que se refere aos resultados obtidos através do modelo proposto.

Portanto, recomenda-se que o modelo sugerido neste estudo seja aplicado em organizações que possuem restrições na definição e mensuração dos processos. Consequentemente, novas ideias e sugestões podem surgir ao aplicar tais conceitos, comprovando a necessidade de ampliar os estudos e buscar novas referências.

\section{Referências}

BESSANT, J.; CAFFYN, S.; GALLAGHER, M. An evolutionary model of continuous improvement behavior. Technovation, Filadélfia, Estados Unidos da América, v. 21, n. 1, p. 67-77, 2001.

BRIALES, J. Melhoria contínua através do Kaizen: Estudo de caso Daimler Chrysler do Brasil. 156p. Dissertação (Mestrado em Sistema de Gestão) Programa de Mestrado em Sistema de Gestão pela Qualidade Total. Universidade Federal Fluminense, Rio de Janeiro, 2005.

CAREgnAto, R; MUTTI, R. Pesquisa Qualitativa: Análise de discurso versus análise de conteúdo, Porto Alegre, Brasil, 2006, 6f.

CHOWDHURY, S. O Sabor da Qualidade: Uma História sobre como criar uma cultura de excelência nas empresas. Rio de Janeiro, Brasil, 2005.

DEMING, W. E. Qualidade: A revolução da Administração. Rio de Janeiro, Brasil, 1990. FREITAS, H.; JANISSEK-MUNIZ, R.; BAULAC, Y.; MOSCAROLA, J. Pesquisa Via Web:

Reinventando o papel e a ideia de pesquisa. Canoas: Sphinx, Brasil, 2006.

GEROLAMO, M. C. Proposta de sistematização para o processo de melhorias e mudanças de desempenho. Dissertação (Mestrado em Engenharia de Produção), Escola de Engenharia de São Carlos, Universidade de São Paulo, São Paulo, Brasil, 2003.

GHINATO, P. Sistema Toyota de Produção: Mais do que simplesmente just-intime, Porto Alegre, Brasil, 1996.

GOLDRATT, The Institute. The Theory of Constraints and its Thinking Process, 2001. HRONEC, S. M. Sinais Vitais: Usando medidas de desempenho da qualidade, 
tempo e custo para traçar a rota para o futuro de sua empresa, São Paulo: Makron Books, Brasil, 2001. 240p.

MACHADO, R.; FRANCISCO, A. C. Melhoria Contínua como ferramenta para o aumento da competitividade organizacional: um estudo de caso no setor metal metalúrgico. Paraná, Brasil, 2005.

MADS L. Análise de Conteúdo: estudo e aplicação. Logos Revista de Divulgação Científica da Ulbra, Canoas, Brasil, v. 5, n. 1, p. 53-58, 1993.

MARTINS, R. A. Sistemas de medição de desempenho: um modelo para estruturação do uso. 1998. Doutorado (Tese), Escola Politécnica, Universidade de São Paulo, São Paulo, Brasil, 1998.

MARTINS, R. A. Uso da informação sobre desempenho como direcionador de projeto de sistemas de medição de desempenho. Em: XXII Encontro Nacional de Engenharia de Produção e VIII International Conference on Industrial Engineering and Operations Management, 2002, Pontifícia Universidade Católica do Paraná, Curitiba, Brasil, 2002.

MATTAR, F. Pesquisa de Marketing: metodologia, planejamento, execução, análise. São Paulo: Elsevier, Brasil, 1994.

MOREIRA, H.; CALEffE, L. G. Metodologia da Pesquisa Para o Professor Pesquisador, Rio de Janeiro: Lamparina, Brasil, 2008.

NEELY, A. Measuring business performance. The Economist Newspaper and Profile Books, Londres, Reino Unido, 1998.

NEELY, A.; AUSTIN, R., Measuring Operations Performance: past, present and future. Em: NEELY, A. (ed.) Performance Measurement - past, present and future. Centre for Business Performance, Cranfield, Reino Unido, p. 419-426, 2000.

OLIVEIRA, O. J. Pequena empresa no Brasil: um estudo de suas características e perspectivas. Integração, São Paulo, Brasil, v. 11, p. 5-15, 2006.

ROBBINS, S. P. Comportamento Organizacional, 9.ed. São Paulo: Prentice Hall, Brasil, 2002. 637p.

RODRIGUES, M. V. C. Entendo, aprendendo, desenvolvendo qualidade padrão seis sigma, Rio de Janeiro: Qualitymark, Brasil, 2006. 112p.

SAMPIERI, R. H.; COLLADO, C. F; LUCIO, M. P. B., Metodologia de Pesquisa, São Paulo: Penso, Brasil, 2013. 624p.

SCARTEZINI, L. M. B. Análise e Melhoria de Processos, Goiás, Brasil, 2009. 
THOMPSON, Jr, STRICKLAND III, A. (2000): Planejamento estratégico: elaboração, implementação e execução, Pioneira, São Paulo.

YIN, R. K. Estudo de Caso: Planejamento e Métodos, Porto alegre: Bookman, Brasil, 2005. 